Published in final edited form as:

Soc Sci Res. 2011 July 1; 40(4): 1196-1213. doi:10.1016/j.ssresearch.2011.03.008.

\title{
A Sort of Homecoming: Incarceration and the housing security of urban men
}

\author{
Amanda Gellera and Marah A. Curtis ${ }^{b}$ \\ Amanda Geller: abg2108@columbia.edu; Marah A. Curtis: mcurtis@bu.edu \\ a Columbia University, Schools of Social Work and Law, 1255 Amsterdam Avenue, New York, NY \\ 10027, USA. Phone: (212)851-2380. Fax: (212)851-2206 \\ b Boston University, School of Social Work, 264 Bay State Road Boston, MA 02215, USA
}

\begin{abstract}
While individuals returning from prison face many barriers to successful re-entry, among the most serious are the challenges they face in securing housing. Housing has long been recognized as a prerequisite for stable employment, access to social services, and other aspects of individual and family functioning. The formerly incarcerated face several administrative and de facto restrictions on their housing options; however, little is known about the unique instabilities that they face. We use a longitudinal survey of urban families to examine housing insecurity among nearly 3,000 urban men, including over 1,000 with incarceration histories. We find that men recently incarcerated face greater housing insecurity, including both serious hardships such as homelessness, and precursors to homelessness such as residential turnover and relying on others for housing expenses. Their increased risk is tied both to diminished annual earnings and other factors, including, potentially, evictions from public housing supported by Federal "one-strike" policies.
\end{abstract}

\section{Keywords}

incarceration; housing; social exclusion

\section{Introduction}

\begin{abstract}
Housing security has long been recognized as an input into the economic, physical, and emotional health of individuals and their communities, particularly for people vulnerable in other aspects of their life, such as those in substance abuse or mental health treatment, or entitled to public benefits such as Supplemental Security Income. (Bradley et al. 2001; Lee, Tyler and Wright 2010; Postmus et al. 2009). Access to stable housing has also been cited as a key support for women facing intimate partner violence (Postmus et al. 2009), and a prerequisite to both obtaining and maintaining employment (Bradley et al. 2001). Aspects of housing instability, on the other hand, such as evictions, frequent moves, overcrowded conditions, or difficulty paying rent, have been associated with adverse outcomes, including
\end{abstract}

() 2011 Elsevier Inc. All rights reserved.

Correspondence to: Amanda Geller, abg2108@columbia.edu.

Publisher's Disclaimer: This is a PDF file of an unedited manuscript that has been accepted for publication. As a service to our customers we are providing this early version of the manuscript. The manuscript will undergo copyediting, typesetting, and review of the resulting proof before it is published in its final citable form. Please note that during the production process errors may be discovered which could affect the content, and all legal disclaimers that apply to the journal pertain. 
delayed medical care and increased use of acute services among children and adults (Kushel et al. 2005; Ma, Gee and Kushel 2008; Reid, Vittinghoff and Kushel 2008).

Despite the documented importance of secure and affordable housing, individuals returning from prison, while known to be both a socially and economically vulnerable population (Petersilia 2003; Western 2006), face severe administrative and de facto barriers to attaining it. Landlords may exclude them from the private housing market, through both cost constraints and background checks. Further, the public housing system's "one strike and you're out" laws grant wide discretion to Public Housing Authorities (PHAs) to exclude or evict residents with criminal histories, and may also place the family members of exoffenders at risk of eviction if they welcome their formerly incarcerated relative home after his sentence is served. Living with friends and family may also be an unsustainable option, particularly if relationships were strained before or during the period of incarceration (Comfort 2008; Edin, Nelson and Paranal 2004; Petersilia 2003; Roman and Travis 2006; Western 2006).

Recent years have seen substantial advances in our understanding of homelessness and housing insecurity (Lee et al. 2010), and particularly our understanding of the potential reciprocal relationship between homelessness and incarceration (Metraux, Roman and Cho 2007). However, the literature to date is based largely on samples of individuals returning from prison and jail, examining their experiences of homelessness, recidivism, and reincarceration. Far less is known about other aspects of housing insecurity, which may precede or follow homelessness, or how the experience of housing insecurity differs between formerly incarcerated individuals and others facing socioeconomic disadvantage.

In this analysis, we use a large longitudinal survey of urban families to assess the levels of housing instability experienced by formerly incarcerated men, and the extent to which this instability is unique to the formerly incarcerated. Using a series of cross-sectional and longitudinal regression models, we estimate the associations between incarceration and men's likelihood of homelessness or eviction, ability to pay their rent or mortgage, frequent residential moves, or "doubling-up" and moving in with friends or relatives because of financial hardship. Although our analysis is based on observational data, and thus unable to definitively identify causal effects, we use detailed measures of socioeconomic disadvantage, and controls for past housing insecurity, to reduce the likelihood that observed relationships are confounded by factors other than incarceration. Any increased housing risk observed among the formerly incarcerated would thus suggest a need for increased attention to this population not only from housing authorities and social service providers, but also policymakers involved in the re-entry process.

\subsection{Background}

1.1.1. Housing Security and Prisoner Re-Entry-The importance of housing security is well documented, and housing insecurity is viewed by many as an indicator of severe social exclusion (Lee et al. 2010). Moreover, the stability that housing provides is particularly salient for ex-prisoners. Returning prisoners have high rates of health, mental health, and substance use problems (Roman and Travis 2006), and treatment for these conditions is more easily accessible for those who have housing (Bradley et al. 2001). The National Commission on Correctional Health Care estimated that 98,000 to 145,000 inmates with HIV were released in the year 1996 alone. Returning prisoners also have high rates of tuberculosis, hepatitis B, and hepatitis C. These illnesses, particularly HIV, require expensive and ongoing treatment, and housing stability is often a prerequisite to obtaining continuous care (ibid). 
Housing also takes on particular importance for returning prisoners because of their need for employment, and the challenges they face in finding it. Employers generally require an address on a job application, and need to be able to contact potential employees during the application process. The difference between having stable and unstable housing can be the difference between obtaining a job or not (Bradley et al. 2001), and can exacerbate the barriers to employment already facing individuals returning from prison (Western, Kling and Weiman 2001).

Moreover, housing can have a direct impact on recidivism rates. Many violations of public order, such as sleeping in public and loitering are common manifestations of homelessness, but leave an individual at risk of summons or arrest (Center for Poverty Solutions 2002). Unstable housing also has the potential to disrupt a returning prisoner's contact with his parole officer. Roman and Travis (2006) cite a significant link between housing sustainability and recidivism, with ex-prisoners facing an increased likelihood of rearrest with every change of residence. Travis, Solomon and Waul (2001) examine a small sample of returning prisoners in New York State and find that individuals returning to a homeless shelter are seven times more likely to abscond from parole than those who returned to a more stable situation. Likewise, Metraux and Culhane (2004) examine a cohort of nearly 50,000 New York State prison releasees, and find that those who become homeless following their time in prison are at significantly greater risk of re-incarceration.

1.1.2. Barriers to Housing Security-There are a number of mechanisms through which incarceration risks compromising prisoners' housing security upon re-entry. Housing stability may be compromised by the stigma of incarceration, lack of financial resources, difficulty securing employment, short or poor credit history, restricted access to welfare benefits and subsidized housing, as well as strained familial relationships (Metraux et al. 2007). Each of these challenges stand to increase the risk of housing insecurity, above and beyond the precarious circumstances that commonly precede incarceration.

In the private rental market, property managers have the right to exclude individuals from their buildings, and many use criminal history as a criterion for doing so. Whether having a criminal record is a good proxy for being a "risky" tenant or not, it is clear that these housing seekers would be at a disadvantage compared to other low-income applicants; twothirds of the 196 property managers surveyed by Helfgott (1997) reported requiring housing applicants to disclose any criminal record information, and $43 \%$ indicated that they would be reluctant to accept the application of anyone convicted of a crime, citing neighborhood safety and "values" as key concerns (Helfgott 1997). In certain cases, such as those of sex offenders, individuals released from prison may also be legally prohibited from living in circumscribed areas (Metraux et al. 2007).

In addition, the challenges that formerly incarcerated individuals face in the labor market may limit their ability to pay for housing (Petersilia 2003; Western 2006). Even if employment is secured, a limited credit and/or rental history may make the formerly incarcerated individual a less desirable tenant than others with the same income. Their ability to pay may be further compromised by the welfare restrictions placed on exoffenders. For example, the Personal Responsibility and Work Opportunity Reconciliation Act of 1996 (PRWORA) required states to at least temporarily deny Temporary Assistance to Needy Families (TANF) benefits and food stamps to anyone convicted of a drug-related crime (Petersilia 2003). Nearly half of states have used their discretionary regulation to impose a lifetime ban on welfare receipt, while the remaining 28 states deny benefits temporarily (Petersilia 2003). These regulations place individuals convicted of drug crimes at even further disadvantage in their attempts to afford secure housing. 
While many individuals unable to afford the private housing market turn to government assistance and public housing, most returning from jail or prison have no such option. Three amendments to the United States Housing Act of 1937 - the Anti-Drug Abuse Act of 1988, the Housing Opportunity Extension (HOPE) Act of 1996, and the Quality Housing and Work Responsibility Act of 1998 - led to a "one strike and you're out" style of enforcement in Public Housing Authorities (PHAs). In these "one strike" policies, PHA's were permitted and in many cases required, to evict and exclude from the application process for a "reasonable amount of time" any household containing a person with a felony conviction, a background of drug-related offenses or violent criminal activity, or anyone with a background of criminal activity that the PHA believes would endanger the health or safety of the community. The public safety risk of the tenants and applicants is left to the discretion of the PHA, as is the length of time considered "reasonable" for exclusion. The 1996 "OneStrike Policy" also mandated that all PHAs use a case review containing stringent background checks on applicants and all household members. In addition, PHAs are required to exclude households with a member who has been previously evicted for a drugrelated offense for a period of three years, and to evict and exclude those subject to lifetime sexual offender registration (United States Department of Housing and Urban Development 1997). In Title V of the Quality Housing and Work Responsibility Act of 1998, Congress recommended that PHAs use data from the National Crime Information Center to screen applicants, and that they may evict or bar admission if any member is using controlled substances (Lundgren, Curtis and Oettinger 2010).

While the total number of individuals excluded from public housing due to one-strike policies is unknown, (Human Rights Watch 2004) finds 46,657 people denied public housing from PHAs in 2002. Still more were excluded from Section 8 housing, and the total, provided by the US Department of Housing and Urban Development (HUD) is likely to undercount individuals whose PHAs do not report their numbers to HUD. Human Rights Watch (2004) estimates that more than 3.5 million people would be denied access to housing assistance as the result of One-Strike Policies. Venkatesh (2002) finds that these restrictions also have implications for family reunification, as family members without criminal histories place their access to public housing in jeopardy by welcoming formerly incarcerated relatives and partners back into their homes.

Formerly incarcerated individuals may also be precluded from moving in with friends and family due to the strains that incarceration places on personal relationships. In addition to the stigma of criminal involvement, incarceration incapacitates prisoners from their family lives, and may preclude visitation (Comfort 2008; Edin et al. 2004). Women may form new relationships while their partner is incarcerated, and incarceration frequently leads relationships to dissolve (Western 2006). Living rent free with family or friends or "doubling up" may be a temporary solution to avoid homelessness but is not likely sustainable in the long term (Bolland and McCallum 2002). Finally, even in the absence of such strain, individuals returning from prison may be subject to parole restrictions against living with others who have been criminally involved, which may rule out a move in with family or friends (Petersilia 2003).

1.1.3. Empirical Evidence-A substantial literature comments upon the difficulties faced by returning prisoners (See Petersilia 2003 for a review), and housing insecurity frequently plays a role in these challenges. Ethnographic research identifies a "nexus" in which the risks of incarceration and homelessness reinforce each other and exacerbate the marginalization faced by severely disadvantaged individuals (Gowan 2002). However, little is known about the extent to which men returning from prison and jail face greater housing challenges than other disadvantaged men. The incarcerated population is overwhelmingly young, minority, and economically disadvantaged, with low levels of education, and most 
would face substantial challenges even in the absence of incarceration (Petersilia 2003; Western 2006).

Much of the evidence documenting housing instability among ex-offenders is based on small convenience samples of men and women recently released from jail and prison (Herbert 2005; LaVigne and Parthasarathy 2005; Travis et al. 2001). These analyses are thus unable to distinguish housing insecurities that are unique to the formerly incarcerated population, from those insecurities related to pre-existing disadvantage, which may have also led to the individuals' incarceration. Even larger studies that focus on ex-prisoners, while able to predict housing risk with a variety of pre-incarceration conditions (Greenberg and Rosenheck 2008; Metraux and Culhane 2004), are limited in their comparisons and unable to distinguish homelessness among the formaly incarcerated from the risks of homelessness faced by other disadvantaged individuals.

A smaller set of analyses seeks to identify the effects of incarceration on housing instability using individuals' reports of their housing circumstances before, as well as after, their time incarcerated. A Center for Poverty Solutions (2002) study randomly samples individuals receiving emergency food assistance at soup kitchens and drop-in centers, and finds high rates of current homelessness (31\%) and low rates of housing stability (30\% in permanent housing) among those with incarceration histories. More than $30 \%$ of formerly incarcerated respondents suggested that their incarceration experience negatively impacted their ability to obtain stable housing, and many indeed recalled more stable housing circumstances before their incarceration than after. Likewise, Dyb (2009) examines a group of recently incarcerated individuals in Norway, and finds reports of homelessness (broadly defined) were significantly higher at the time of release from prison than interviewees recalled from before their incarceration. However, the differences observed in this line of research are based on retrospective measures of pre-incarceration housing, and participant recall may compromise the validity of these findings.

\subsection{This Study}

The current analysis uses a detailed, population-based, longitudinal survey of urban families to identify several housing hardships experienced by formerly incarcerated men. We examine the extent to which post-incarceration hardships exceed those faced by other disadvantaged men, and the extent to which formerly-incarcerated men face greater insecurity after their time in prison and jail than they did before. We also assess two potential explanations for observed differences in housing instability, each of which stands to suggest a different policy response: reductions in earnings, and restrictions governing public housing residence. In so doing, we stand to substantially advance our understanding of the links between incarceration and housing instability.

\section{Material and Methods}

\subsection{Data Source}

Data are drawn from the Fragile Families and Child Wellbeing study ("Fragile Families"), funded by grants from the Eunice Kennedy Shriver National Institute of Child Health and Human Development (NICHD) and a consortium of private foundations. This study was constructed to allow researchers to understand the challenges and capacities facing a sample of mostly unwed urban parents and the determinants and trajectories of their relationships and contains detailed questions on the roles and circumstances of fathers and a variety of aspects of social and material disadvantage, including both housing instability and experience in the criminal justice system. This study follows a cohort of nearly 5,000 couples with children born between 1998 and 2000 in twenty large U.S. cities randomly 
sampling births in 75 hospitals. By design, approximately three quarters of the interviewed mothers were unmarried. Face-to-face interviews were conducted with 4,898 mothers while they were still in the hospital after giving birth and nearly $80 \%$ of fathers were surveyed as well (see Reichman et al., 2001 for a description of the research design)1.

The survey's oversample of unmarried parents produces a sample that is highly disadvantaged, and incarceration is prevalent among the fathers. More than $40 \%$ of the fathers, including more than half those unmarried at their child's birth, have spent time in prison or jail. However, the fathers with no history of incarceration are also relatively lowincome, with low levels of education, and provide a valuable comparison sample for the assessment of incarceration's unique risks. The study surveys both men and their partners at the time of their child's birth, with follow- up surveys conducted when the children are one, three, and five years old.

\subsection{Variables}

2.2.1. Incarceration-Our measure of fathers' incarceration is based on fathers' selfreports, supplemented with additional indicators to reduce the risk of measurement error associated with underreporting (Groves 2004). At each follow-up wave, fathers are asked to self-report whether they have been charged with a crime in the years leading up to the interview; if so, they are asked if they have been convicted, and if so, they are asked if they have been incarcerated 2 . The repeated measurement of incarceration allows the identification of incidents that occur during the period of the survey, and importantly, allows controls for socioeconomic disadvantage and housing insecurity before these incidents take place.

Self-reports are enhanced by "disposition data" recorded by the survey subcontractors, indicating whether a father was incarcerated at the time that they contacted him for followup. The disposition data identify 121 additional incarcerated fathers between baseline and year 3, and another 122 incarcerated fathers at year 5. The incarceration measure also considers mothers' reports of their partners' incarceration: mothers report at years one and three whether their partner has ever been incarcerated, and at year five whether he has been incarcerated in the past two years. Finally, parents' direct reports and disposition data are supplemented with indirect reports of incarceration, in which either parent cites incarceration as a reason the father was separated from their child or was unable to find a job, or some other way that incarceration affected their lives. Few fathers with incarceration histories were identified from indirect reports alone $(6 \%$ of those reporting any incarceration before year 5).

2.2.2. Housing Insecurity-Housing security and insecurity exist along a continuum from consistent stable housing to chronic homelessness. Where researchers and policymakers draw the line is important both conceptually and analytically. The most severe form of insecurity, homelessness, is most commonly defined using the federal guidelines (42 USC Sec. 11302), by which one is homeless if he or she lacks a "fixed, regular, and adequate nighttime residence", lives in temporary accommodations (e.g, shelters, transitional housing, or welfare hotels), or sleeps in public or private spaces not intended for sleeping (e.g., cars or abandoned buildings). However, other housing conditions may also

\footnotetext{
${ }^{1}$ Study background, documentation, and data collection instruments, as well as a list of published studies, can be found on the FFCWB website: http://www.fragilefamilies.princeton.edu/documentation.asp.

${ }^{2}$ Due to an error in survey development, parents are asked to self-report whether they have been charged and convicted between years three and five, but are not asked to self-report incarceration. The vast majority of fathers report to have not been arrested or convicted (and thus not incarcerated), and a handful are reported by their partner or another source as having been incarcerated. Only 14 are left with ambiguous incarceration status.
} 
represent a "manifestation of the same underlying relationship between housing costs and household resources" (Honig and Filer 1993). Researchers have variously used eviction, frequent moves, difficulty paying rent, spending more than $50 \%$ of household income on housing, doubling up, and living in overcrowded conditions, as symptoms of housing instability (Gilman et al. 2003; Kushel et al. 2005; United States Department of Housing and Urban Development 2003). An examination of homelessness reveals several risks posed by severe housing insecurity, and links between homelessness and other housing hardships. The majority of homeless people experience other forms of housing instability prior to becoming homeless; likewise, many people who are formerly homeless return to situations that continue to be insecure. Those experiencing housing insecurity are more likely to have been homeless at some point, or to become homeless in the future, compared to the stably housed (Reid et al. 2008).

In order to capture the full continuum of housing insecurity and the relevance of its component parts for the formerly incarcerated, we measure housing insecurity based on respondents' living condition at the time of each follow-up survey, and whether he indicates any housing hardships in the year leading up to his survey. For example, respondents are considered insecure if they indicate homelessness (per the federal definition), eviction, or living with others but paying no rent. 3 Doubling up and living with others without paying rent often precedes spells of homelessness (Bolland and McCallum 2002; Rossi 1989) and is increasingly recognized as a potentially unstable arrangement (Homeless Emergency Assistance and Rapid Transition to Housing Act 2009). They are also considered insecure if they indicate that they had been forced, due to financial constraints, to move in with family or friends, were unable to pay their full rent or mortgage, or if they moved residences more than once per year in the last wave. Frequent moves are destabilizing and associated with negative outcomes (Gilman et al. 2003). We examine each of these hardships as a separate, but related dimension of housing insecurity.

We limit our analysis sample to those individuals responding to all questions indicating housing insecurity at year 5 , and not reporting incarceration as their living situation at the time of their five-year survey, leaving a full analysis sample of 2,768. We anticipate that both incarceration and housing insecurity are less prevalent among our analysis sample than those who we fail to observe. Not only are more disadvantaged survey respondents more likely to attrite, the housing- insecure in particular are difficult for surveyors to locate and contact. The possibility therefore exists that our estimates are actually a lower bound on the insecurity experienced by both our incarcerated and never-incarcerated sample.

Table 1 details the prevalence of each type of housing security among our analysis sample. The first column suggests a de facto rank-ordering of each type of housing instability: while $21 \%$ of those in our analysis sample experience some sort of insecurity in the fifth year of the survey, some forms of housing insecurity are far more common than others. More than $10 \%$ of the men interviewed report having skipped a mortgage or rent payment in the past year, and approximately $6 \%$ report having moved in with others to save money (or "doubling up"). $5 \%$ report having moved at least three times in the two years leading up to the survey, $3 \%$ report living with others but not paying rent, and $2 \%$ each report having been evicted or homeless (i.e., living in a shelter or elsewhere not intended for residence) in the past year. The relative rarity of events such as eviction and homelessness underscore the

\footnotetext{
${ }^{3}$ The Hearth Act PL 111-222 (2009) expands the definition of homelessness to include individuals or families who are losing their housing in 14 days and lack support networks or resources to obtain housing (those living with others and not paying rent or doubling up who face imminent loss of this arrangement are explicitly included) as well as those who have moved very frequently and are likely to continue to do so because of chronic physical health or mental health conditions. Particularly important for individuals recently released from prison, the new definition of homelessness includes individuals or families who resided in a shelter or in a venue not intended for habitation or are exiting an institution where temporarily living.
} 
severity of the conditions. Table 1 also shows that housing insecurity is significantly more prevalent among respondents with histories of incarceration. Overall insecurity rates are more than twice as high among formerly incarcerated respondents, and the disparities are even more pronounced for the most serious types of hardship.

2.2.3. Control Variables-Although men with incarceration histories experience greater housing insecurity than those never incarcerated, formerly-incarcerated and neverincarcerated men also differ on a number of other dimensions that are likely to influence both their probability of incarceration and their housing stability. We identify a number of demographic and socioeconomic factors, listed in Table 2, that have been tied to both incarceration risk and housing instability, and assess differences on these measures between men with and without incarceration histories. The first set of covariates are those established early in life, including demographic characteristics such as race, immigrant background, and family history, as well as behavioral traits such as cognitive ability and impulsivity, which are linked by control theorists to criminal activity (Farrington 1998; Gottfredson and Hirschi 1990), and may increase or impede the ability to manage finances and remain stably housed (Dickman 1990). We define family history as whether respondents were living with their two biological parents at age 15, and whether their own mother had a history of mental health problems. Challenges in one's family of origin, such as parental mental illness or growing up without both biological parents, have been tied to negative adult outcomes, which may be correlated with the risk of both incarceration and housing insecurity (Garfinkel and McLanahan 1986).

Respondents' cognitive ability is measured with the Wechsler Adult Intelligence ScaleRevised (Wechsler 1981), and impulsivity is measured with the Dickman (1990) scale of dysfunctional impulsivity. Although the measures were administered during follow-up data collections, they are considered stable constructs, unlikely to be affected by previous incarceration spells. If, however, impulsivity and cognitive ability are altered by an incarceration experience, including them in the analyses will underestimate the effects of incarceration.

The second set of covariates contains those observed at or around the time the respondents' focal child was born. These include age and education, and a rich set of employment, behavioral, and family characteristics. We control for their relationship status (married vs. cohabiting vs. nonresident) at the time of the birth, since unmarried men tend to be at greater risk for criminal behavior (Sampson and Laub 1990), and because family structure, and partnership instability in particular, may result in fathers moving in and out of the household with their partner and child. Nonresident fathers may also lack the family supports that are often pivotal for men returning from jail and prison. We also control for several factors reflecting parents' labor market potential, health, and substance use patterns. Each of these measures is both associated with incarceration risk (Western 2006) and likely to compromise housing security. Finally, because an individual's likelihood of incarceration is tied not only to their own behavior but also to the policies governing their local criminal justice system, and because their likelihood of housing insecurity is tied to the conditions of local housing markets, we include city fixed effects in all models.

As Table 2 indicates, respondents with incarceration histories face considerable disadvantage when compared to those who have never been to prison or jail. They are far more likely to be racial and ethnic minorities, less likely to have grown up in a two-parent household, and more likely to have a history of depression in their families. They score higher on the Dickman scale of impulsivity, are younger and in worse health when their focal child is born, and are less likely to be married to or living with the child's mother. Further, they are markedly less educated, less likely to be employed, and are more likely to 
report problems with substance abuse. These differences, with few exceptions, are highly statistically significant, and each would, even in the absence of incarceration, likely compromise their ability to remain stably housed.

While these covariates provide a detailed description of respondents' life circumstances at the time of their focal child's birth, these descriptors may not be entirely exogenous, and may be affected by earlier contact with the criminal justice system. Men enter our sample upon the birth of a child, but among those men who have been to jail or prison, their median reported age of first incarceration is 20, an average of six years before the focal child's birth. To the extent that earlier incarceration precedes men from fatherhood or education, or affects their relationship or other characteristics at the child's birth, models including these covariates may underestimate the true effect of having been to jail or prison. To better estimate incarceration's causal effects, net of exogenous life circumstances, we focus our analyses, detailed below, on incarceration spells that follow the first-year survey.

\subsection{Modeling Strategy}

2.3.1. Basic Estimation-Table 1 shows significantly higher rates of housing insecurity among men with incarceration histories, and we assess the extent to which this relationship can be explained by demographic, socioeconomic, and behavioral conditions that influence the likelihood of both incarceration and instability. To do this, we estimate a series of logistic regression models, predicting whether respondents indicate experiencing any insecurity in the year leading up to the five-year survey with their lifetime incarceration history and the "early-life covariates" listed in Table 2, denoted here as $\boldsymbol{X}_{\boldsymbol{I}}$. We then replicate Model 1 for each of the individual housing instability items listed in Table 1.

$$
\operatorname{Logit}(\text { INSECURE })=\beta_{0}+\beta_{1} \text { LIFETIMEINC }+\beta_{2} \boldsymbol{X}_{1}+\varepsilon
$$

Model 1 estimates disparities in housing insecurity between men with and without histories of incarceration, and adjusts for several important correlates of both incarceration and socioeconomic disadvantage-however, the possibility remains that $\beta_{1}$, the estimated relationship between incarceration and housing insecurity, is biased by the omission of other factors that might be correlated with both lifetime incarceration and insecurity. We therefore estimate a second model that includes a second set of variables, $\boldsymbol{X}_{2}$, measured at baseline and the one-year survey. These variables, the "contemporaneous covariates" in Table 2 , are likely to be correlated with both incarceration and housing insecurity. In fact, these covariates (particularly factors such as employment or education) could themselves be influenced by early incarceration incidents (if, for example, an early incarceration affects later labor market prospects). To avoid bias resulting from this influence, we consider our lifetime incarceration variable in two stages: we define a variable $I N C_{15}$ to indicate whether the respondent reports having been incarcerated between years 1 and 5 , and a variable $I N C_{1}$ to indicate whether the respondent reports having been incarcerated prior to year 1 . Because $I N C_{1}$ could be causally linked to the covariates in either direction, our focus in interpretation will be on $I N C_{15}$.

$$
\operatorname{Logit}\left(I N S E C U R E_{5}\right)=\beta_{0}+\beta_{1} I N C_{15}+\beta_{2} I N C_{1}+\beta_{3} \boldsymbol{X}_{1}+\beta_{4} \boldsymbol{X}_{2}+\varepsilon
$$

To further isolate the relationship between incarceration and housing insecurity, we examine the extent to which housing security changes following time spent in prison or jail. In Model 3 we predict men's likelihood of insecurity at year five based not only on their incarceration 
history and socioeconomic covariates, but also on their experience of housing insecurity at the one-year survey. In this model, $\beta_{1}$ represents not the level difference in the likelihood of housing insecurity, but the extent to which the likelihood of insecurity changes for incarcerated men, beyond the change experienced by men not incarcerated. Where possible, the vector INSECURE $\boldsymbol{E}_{\boldsymbol{1}}$ contains indicators of each type of insecurity presented in Table 1, measured at year 1 . In cases where including each aspect of insecurity prevented the model estimation from converging, INSECURE $\boldsymbol{I}_{\boldsymbol{l}}$ contains a single indicator of whether the respondent experienced any of the six hardships.

$\operatorname{Logit}\left(I N S E C U R E_{5}\right)=\beta_{0}+\beta_{1} I N C_{15}+\beta_{2} I N C_{1}+\beta_{3} \boldsymbol{X}_{1}+\beta_{4} \boldsymbol{X}_{2}+\beta_{5} \boldsymbol{I N S E C U R E _ { 1 } + \varepsilon}$

2.3.2. Income and Insecurity-After estimating an average relationship between incarceration and housing insecurity in Models 1 through 3, we next examine the extent to which this relationship is driven by a reduction in earnings, and the extent to which it is driven by other factors. The labor market challenges associated with incarceration are well established, and are likely to contribute to the inability of formerly incarcerated men to remain stably housed. In Model 4, we replicate the estimation of Model 3, but include an additional control for annual earnings at year five, after any incarceration has occurred. An insignificant $\beta_{1}$ in this model would indicate that at equal earnings, men with and without incarceration histories have similar risks of insecurity, and suggest that income support might be the best mechanism for overcoming the housing instability associated with incarceration.

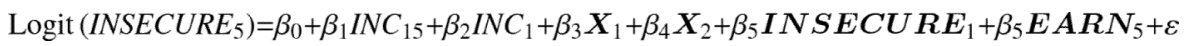

2.3.3. Incarceration and Public Housing - In addition to examining the relationship between incarceration, housing, and earnings, we also test another potential link between incarceration and housing insecurity: the administrative and legal barriers facing exoffenders. Specifically, in Model 5 we examine the "one-strike" policy governing criminal activity in public housing projects, and examine if incarceration is associated with greater instability for those men whose families were in public housing prior to his time in prison or jail. We define a binary variable $P H_{1}$, which takes on a value of 1 for the 456 men who were either living in public housing at year 1, or whose partners were living in public housing at that time (216 of the men in our analysis sample report living in public housing themselves, the other 240 had partners report living in public housing).

$\operatorname{Logit}\left(I N S E C U R E_{5}\right)=\beta_{0}+\beta_{1} I N C_{15}+\beta_{2} I N C_{1}+\beta_{3} X_{1}+\beta_{4} X_{2}+\beta_{5}$ INSECU RE $E_{1}+\beta_{5} P H_{1}+\beta_{6} I N C_{15} * P H_{1}+\varepsilon$

In Model 5, the coefficient $\beta_{5}$ represents the average increased (or reduced) likelihood of housing insecurity faced by men in public housing at year 1 , and the coefficient $\beta_{6}$ represents the increase (or reduction) in the relationship between incarceration and housing insecurity for men whose families were in public housing before their incarceration. A positive and significant $\beta_{6}$ would suggest that incarceration presents a greater risk of insecurity for men in public housing, perhaps related to "one- strike" policies and related factors. 


\section{Results and Discussion}

\subsection{Incarceration and Housing Insecurity}

Table 1 suggests significantly higher rates of housing insecurity among men who have been incarcerated, and our regression models further support this relationship. Table 3 presents odds ratios indicating the estimated increase in the odds of insecurity faced by incarcerated men in the past year, and Table 4 presents comparable estimates for models predicting the most serious form of housing insecurity, past-year homelessness (i.e., "spending at least one night in a shelter [or car or other place not intended for residence]"). Tables examining other forms of housing insecurity are provided in an Appendix.

Examining our broad indicator of housing insecurity, and the adjusted difference by lifetime incarceration status, we find that men who have been incarcerated at some point in their lives face odds of insecurity that are nearly twice as high as those faced by men never incarcerated. In addition to this difference being statistically significant, it is of considerable magnitude; the gap in likelihood of insecurity is greater between the formerly and never incarcerated than it is between either blacks and whites, or Hispanics and whites.

When focusing only on recent incarcerations (i.e., between Years 1 and 5, in Model 2) and controlling for a more extensive list of demographic and socioeconomic covariates, the differences associated with incarceration are less pronounced. Nonetheless, they remain strong and statistically significant, with recently incarcerated men facing $69 \%$ greater odds of insecurity than those not incarcerated in the most recent wave. Differences by incarceration status also remain strong and statistically significant in Model 3, when earlier indicators of housing instability are also controlled for. In fact, the estimates for Models 2 and 3 differ only slightly, suggesting that the relationship between incarceration and later housing insecurity is fairly robust.

Examining homelessness in Table 4, we find that differences by incarceration status follow similar patterns, but are even starker. Formerly incarcerated men face odds of homelessness that are nearly four times as high as those for never-incarcerated men (Model 1). As with the broader measure of housing insecurity, homelessness gaps narrow when focusing on recent incarceration and including additional covariates (Model 2). Nonetheless, even controlling for earlier insecurity and other demographic and socioeconomic covariates (Model 3), recently incarcerated men face odds of homelessness that are more than twice as high as those of men not recently incarcerated.

Tables A.1, A.2, A.3, A.4, and A.5 show similar patterns for other dimensions of housing insecurity, though levels of statistical significance vary by the outcome of interest. Namely, differences in frequent moves and "living with others without paying rent" are consistently statistically significant, while differences in skipping a mortgage payment, eviction, and doubling up lose significance as additional covariates are controlled.

\subsection{Incarceration and Earnings}

For each of our primary outcomes (Any Insecurity and Homelessness), Model 4 examines the link between incarceration and housing in the context of post-incarceration income. To the extent that the housing insecurity faced by formerly incarcerated men is tied to their limited earning potential, transitional jobs programs, and other initiatives to improve the labor market prospects of ex-prisoners, are likely to have the added benefit of improving their housing security. The findings in Tables 3 and 4 indeed suggest a protective relationship between income and housing insecurity: men with greater annual earnings at year 5 are significantly less likely to experience any housing insecurity or homelessness. However, even at equal levels of income, men incarcerated between years 1 and 5 
experienced considerably more housing insecurity in terms of the aggregate measure.4 This marginal incarceration relationship, beyond that associated with reduced earnings, suggests that while income and employment supports have the potential to reduce the hardships associated with prison re-entry, housing circumstances might still warrant dedicated attention.

\subsection{Incarceration, Insecurity, and Public Housing}

Model 5 further explores mechanisms through which an incarceration effect compromise housing security by examining the implications of incarceration for public housing residents and their families. While public housing is a support meant to reduce residents' likelihood of instability, the one strike regulations governing access may compromise the stability of formerly incarcerated individuals. The last column of Table 3, for example, suggests that public housing residents are at a lower risk of housing insecurity, although this relationship is not statistically significant. Incarceration, on the other hand, is significantly associated with an elevated risk of housing insecurity. However, given the inclusion of an interaction term in this estimation, the "incarceration" odds ratio measures hardships only for the nonpublic housing population. The relationship between incarceration and insecurity among the public housing population is measured using a t-test of the sum of the "main effects" of incarceration and the interaction term, and also suggests significantly greater risk among these men. The interaction term itself is statistically insignificant, suggesting that the increased risk of housing insecurity is substantively similar for formerly incarcerated men with and without public housing ties. Similar relationships are observed in examinations of homelessness (Table 4).

Most notably, as shown in Table A5, the relationship between incarceration and subsequent eviction is present only for men who were living, or had partners, in public housing prior to their incarceration. The increased risk associated with public housing suggests that Federal one-strike policies do, indeed, succeed in excluding those with a recent conviction from public housing residence. On the other hand, while several of the other hardships faced by men following time incarcerated are more severe among men with previous public housing ties, this relationship is not statistically significant.

\section{Conclusions}

\subsection{Summary of Findings}

As shown in Table 1, and further demonstrated in the regression analyses that follow, housing insecurity is significantly more prevalent among men with histories of incarceration than those who have never been incarcerated. This relationship is robust to controls for a rich array of potential confounders, including, for many dimensions of insecurity, housing circumstances prior to incarceration. Our findings suggest that the housing circumstances of ex-prisoners are likely to be severely compromised upon re-entry. The increased insecurity associated with incarceration is particularly significant among some of the more serious dimensions: formerly incarcerated men face more than twice the odds of homelessness as men who have not been incarcerated. Likewise, they face nearly twice the odds of moving residences more than once per year, and of relying on others for their living expenses. On the other hand, the odds of skipping a mortgage or rent payment, the odds of "doubling up" to save money, and the odds of eviction, are not significantly higher among recently incarcerated men when other forms of social disadvantage are controlled for.

\footnotetext{
${ }^{4}$ High residential trunover is also more likely for recently incarcerated men, controlling for income(see Table A3).
} 
We find that housing insecurity and its relationship with incarceration are closely tied to the limited labor market options available to ex-offenders, with post-incarceration earnings nearly universally associated with reduced housing insecurity. However, the tie between incarceration and housing is also related to factors beyond the labor market: even at equal levels of annual earnings, recently incarcerated men face significantly greater odds of insecurity than their counterparts with no history of recent incarceration, and more residential turnover in particular. In addition, we find that men living in public housing (or with romantic partners in public housing) before their incarceration are more likely to be evicted upon their return, suggesting that targeted housing policy may play a role in the instability facing ex-prisoners.

\subsection{Limitations and Directions for Future Research}

While our analysis represents a major advance in the literature examining the nexus of incarceration and housing insecurity, much remains to be learned. The family focus of the Fragile Families study, and the non-incarcerated comparison sample that it provides, is an important strength of our data; however, the study's focus on parents rather than prisoners limits its generalizability. The vast majority of incarcerated men have children (Western 2006), but incarcerated men without children are likely to differ from incarcerated fathers on many dimensions. Our findings are unlikely to generalize to the approximately $30 \%$ of incarcerated men without children. In addition, while the Fragile Families Study is wellequipped to identify differences between men with and without histories of incarceration, the data are not able to distinguish jail incarcerations from prison incarcerations. Metraux et al. (2007) suggest that patterns of homelessness among individuals released from prison differ substantially from patterns of homelessness among those released from jail. Further research and additional data are needed to identify the extent to which these differences exist in other dimensions of housing insecurity.

Our analyses are also limited by the inherent difficulties in ascertaining causal relationships from observational data. While we find that men's odds of housing insecurity are significantly higher among the formerly incarcerated, these differences might be driven by unobserved heterogeneity between men with and without incarceration histories, rather than by a causal effect of incarceration. The diminished magnitude and significance of the incarceration-insecurity relationship in Model 2, which controls more completely for preincarceration disadvantage than does Model 1, suggests that other aspects of social disadvantage contribute to the relationship. Even including controls for pre-incarceration housing does not completely protect against a spurious relationship; if, for example, the initiation of drug use or changes in use patterns, a job loss or other life shock between the first and fifth-year surveys contributes to both incarceration risk and housing insecurity, even the relationship measured in Model 3 will overstate incarceration's causal effect.

\subsection{Policy Implications}

Nonetheless, our analyses to date reinforce the notion that men returning from prison and jail are a highly vulnerable population. Specifically, our findings suggest that ex-prisoners are at great risk of housing insecurity, and that this risk is tied, but not limited to, their challenges in securing stable employment. Our findings therefore suggest the need for policy solutions both within and beyond the labor market. Many programs have been suggested to try to raise the earnings of people entering the labor market after prison. Most prisons provide at least some education, job training, and work programs, and a recent round of evaluation results suggest that transitional jobs programs, immediately after prison release, are associated with higher earnings (Bloom 2006; Jacobs and Western 2007). Policy advocates have also suggested limiting disqualifications on licensed employment for exfelons, and promoting incentives to hire ex-felons with tax incentives to employers. To the 
extent that these suggestions increase employment among ex-offenders, and improve their financial stability, they also stand to reduce their risk and extent of housing insecurity.

Barriers to affordable housing for men returning from prison can also be addressed directly, through modifications to the "one-strike" restrictions administratively barring ex-offenders from public housing. Although public housing authorities are already granted very wide discretion to consider the individual circumstances of applicant families, the complexity of and financial incentives to enforce (data on one-strike implementation is collected and tied to funding allocations for certain programs) "one strike policies" is likely simplified in implementation by instituting a de facto ban on individuals with an incarceration record. Given that public housing is a very scarce resource, one strike implementation guidelines suggest that reserving this benefit for "those who play by the rules" is consistent with a practice of evicting or pushing applicants with a criminal history to the back of a long queue (HUD 1997, p. 7-8). These policies, and the link between one- strike implementation and more general funding, must be comprehensively evaluated to balance the social costs of this restriction with the risk posed by potential public housing tenants, and the presumed public safety benefits associated with their exclusion.

The challenges facing individuals returning from prison must also be considered throughout the processing of criminal cases, including when sentencing decisions are made and in the time that prisoners spend incarcerated, as well as in re-entry planning. Correctional entities have the potential to play a more active role in providing needed transitional housing and employment support, as well as drug treatment and other services that may enable the retention of safe and stable housing. While there is currently tremendous diversity across agencies in their focus on re-entry planning, Petersilia (2003, Chapter 9) cites several promising initiatives in pre-release programming that may enable returning prisoners to secure and maintain housing and employment. An emphasis on rehabilitation, by community and corrections agencies alike, has the potential to facilitate not only the housing security of ex-prisoners, but their re-entry more broadly.

\section{Acknowledgments}

This work was supported by a grant from the Robert Wood Johnson Foundation. The Fragile Families and Child Wellbeing Study was supported by Grant R01HD36916 from the National Institute of Child Health and Human Development. The contents of the article are solely the responsibility of the authors and do not necessarily represent the official views of the National Institute of Child Health and Human Development. Tim Smeeding, Melinda Sandler Morrill, Christopher Wildeman, and Justin Wolfers provided valuable feedback on earlier versions of this analysis. Allyson Walker, YeaLhim Kim, and Alexander Ramani provided excellent research assistance. All errors and conclusions are those of the authors alone.

\section{Literature Cited}

Bloom, D. Research on Prisoner Reentry: What Do We Know and What Do We Want to Know. Ann Arbor, MI: Gerald R. Ford School of Public Policy, University of Michigan; 2006. EmploymentFocused Programs for Ex-Prisoners: What Have we Learned What Are We Learning, and Where Should We Go From Here?.

Bolland JM, McCallum DM. Touched by homelessness: An examination of hospitality for the down and out. American Journal of Public Health. 2002; 92(1):116-118. [PubMed: 11772773]

Bradley, K.; Oliver, RBM.; Richardson, NC.; Slayter, EM. Policy Brief. Boston, MA: Community Resources for Justice; 2001. No Place Like Home: Housing and the Ex-Prisoner.

Center for Poverty Solution. Barriers to Stability: Homelessness and Incarceration's Revolving Door in Baltimore City. Baltimore, MD: 2002.

Comfort, M. Doing Time Together. Love and Family in the Shadow of the Prison. Chicago IL: University of Chicago Press; 2008. 
Dickman SJ. Functional and Dysfunctional Impulsivity: Personality and Cognitive Correlates. Journal of Personality and Social Psychology. 1990; 58(1):95-102. [PubMed: 2308076]

Dyb E. Imprisonment: A Major Gateway to Homelessness. Housing Studies. 2009; 24(6):809-824.

Edin, K.; Nelson, TJ.; Paranal, R. Fatherhood and Incarceration as Potential Turning Points in the Criminal Careers of Unskilled Men. In: Pattillo, M.; Weiman, DF.; Western, B., editors. Imprisoning America: The Social Effects of Mass Incarceration. New York, NY: Russell Sage Foundation; 2004.

Farrington DP. Predictors, Causes, and Correlates of Male Youth Violence. Crime and Justice. 1998; 24:421-475.

Garfinkel, I.; McLanahan, SS. Single Mothers and their Children. Washington, DC: The Urban Institute Press; 1986.

Gilman SE, Kawachi I, Fitzmaurice GM, Buka L. Socio-economic status, family disruption, and residential stability in childhood: Relation to onset, recurrence, and remission of major depression. Psychological Medicine. 2003; 33(8):1341-1355. [PubMed: 14672243]

Gottfredson, M.; Hirschi, T. A General Theory of Crime. Stanford, CA: Stanford University Press; 1990.

Gowan T. The Nexus: Homelessness and Incarceration in Two American Cities. Ethnography. 2002; 3:500-534.

Greenberg GA, Rosenheck RA. Jail Incarceration, Homelessness, and Mental Health: A National Study. Psychiatric Services. 2008; 50(2):170-177. [PubMed: 18245159]

Groves, RM. Survey Errors and Survey Costs. Hoboken, NJ: Wiley; 2004.

Helfgott J. Ex-offender Needs versus Community Opportunity in Seattle, Washington. Federal Probation. 1997; 61(2):12-24.

Herbert, T. The Invisible Tenant: Living in Federally Assisted Housing after Prison The Invisible Tenant: Living in Federally Assisted Housing after Prison. New York, NY: Family Justice; 2005.

[accessed May 20] "Homeless Emergency Assistance and Rapid Transition to Housing Act 2009" (P.L. 111-222); Division B, Homelessness Reform, Sec. p. 896-32.http://www.hudhre.info/documents/S896_HEARTHAct.pdf

Honig M, Filer RK. Causes of Intercity Variation in Homelessness. American Economic Review. 1993; 83(1):248-255.

Watch, HR., editor. Human Rights Watch. No Second Chance: People with Criminal Records Denied Access to Public Housing. New York, NY: 2004.

Jacobs, E.; Western, B. Report on the Evaluation of the ComALERT Prisoner Reentry Program. Brooklyn, NY: Kings County District Attorney; 2007.

Kushel MB, Gupta R, Gee L, Haas JS. Housing Instability and Food Insecurity as Barriers to Health Care Among Low-Income Americans. Journal of General Internal Medicine. 2005; 21(1):71-77. [PubMed: 16423128]

LaVigne, N.; Parthasarathy, B. Returning Home Illinois Policy Briefs. Washington, DC: Urban Institute; 2005. Prisoner Reentry and Residential Mobility.

Lee BA, Tyler KA, Wright JD. The New Homelessness Revisited. Annual Review of Sociology. 2010; 36:24.21-24.21.

Lundgren LM, Curtis MA, Oettinger C. Postincarceration Policies for Those With Criminal Drug Convictions: A National Policy Review. Families in Society. 2010; 91(1):31-38.

Ma CT, Gee L, Kushel MB. Associations between housing instability and food insecurity with health care access in low-income children. Ambulatory Pediatrics. 2008; 8(1):50-57. [PubMed: 18191782]

Metraux S, Culhane DP. Homeless shelter use and reincarceration following prison release: Assessing the risk. Criminology and Public Policy. 2004; 3:201-222.

Metraux, S.; Roman, CG.; Cho, R. National Symposium on Homelessness Research. Washington, DC: U.S. Department of Housing and Urban Development; 2007. Incarceration and Homelessness.

Pattillo, M.; Weiman, DF.; Western, B. Imprisoning America: The Social Effects of Mass Incarceration. New York, NY: Russell Sage Foundation; 2004. 
Petersilia, J. When Prisoners Come Home: Parole and Prisoner Re-entry. New York, NY: Oxford University Press; 2003.

Postmus JL, Severson M, Berry M, Yoo JA. Women's Experiences of Violence and Seeking Help. Violence Against Women. 2009; 15(7):852-868. [PubMed: 19458091]

Reichman NE, Teitler JO, Garfinkel I, McLanahan S. Fragile Families: sample and design. Children \& Youth Services Review. 2001; 23(4/5):303-326.

Reid KW, Vittinghoff E, Kushel MB. Association between the level of housing instability, economic standing, and health care access: A meta-regression. Journal of Health Care for the Poor and Underserved. 2008; 19(4):1212-1228. [PubMed: 19029747]

Roman CG, Travis J. Where Will I Sleep Tomorrow? Housing, Homelessness, and the Returning Prisoner. Housing Policy Debate. 2006; 17(2):389-418.

Rossi, PH. Down and out in America: The origins of homelessness. Chicago IL: University of Chicago Press; 1989.

Sampson RJ, Laub JH. Crime and Deviance Over the Life Course: The Salience of Adult Social Bonds. American Sociological Review. 1990; 55(5):609-627.

Travis, J.; Solomon, AL.; Waul, M. From Prison to Home: The Dimensions and Consequences of Prisoner Reentry. Washington, DC: Urban Institute; 2001. p. 64

United States Department of Housing and Urban Development. Meeting the Challenge: Public housing authorities respond to the "One Strike and You're Out" initiative. Washington, DC: United States Department of Housing and Urban Development; 1997.

United States Department of Housing and Urban Development. Affordable Housing Needs: A Report to Congress on the Significant Need for Housing. Washington, DC: Office of Policy Development and Research; 2003.

Venkatesh, SA. The Robert Taylor Homes Relocation Study. New York, NY: Columbia University Center for Urban Research and Policy; 2002.

Wechsler, D. Wechsler Adult Intelligence Scale - Revised (WAIS-R Manual). The Psychological Corporation. Harcourt Brace Jovanovich; 1981.

Western, B. Punishment and Inequality in America. New York, NY: Russell Sage Foundation; 2006.

Western B, Kling JR, Weiman DF. The Labor Market Consequences of Incarceration. Crime and Delinquency. 2001; 47(3):410-427.

\section{Appendix}

The tables in this appendix (Tables A1-A5) present the relationships between incarceration, demographic and socioeconomic factors, and five additional measures of housing insecurity (Respectively: Skipping rent or mortgage payments, "doubling up", moving more than once per year, living with others and not paying rent, and eviction.) 
Table 1

Fathers' Housing Instability (Year 5) by Incarceration History

\begin{tabular}{lcccc}
\hline & $\begin{array}{c}\text { Full Sample } \\
\mathbf{N = 2 , 7 6 3}\end{array}$ & $\begin{array}{c}\text { Ever Incarcerated } \\
\mathbf{N = 1 , 0 5 2}\end{array}$ & $\begin{array}{c}\text { Never Incarcerated } \\
\text { N=1,584 }\end{array}$ & $\begin{array}{c}\text { Incarceration History Unknown } \\
\text { N=127 }\end{array}$ \\
\hline Any Instability & $21 \%$ & $31 \%$ & $14 \%$ & $22 \%$ \\
Instability Index (0=none, 6=highest) & $0.29[\mathrm{SD}=0.66]$ & $0.45[\mathrm{SD}=0.83]$ & $0.18[\mathrm{SD}=0.49]$ & $8 \%$ \\
Skipped Mortgage & $11 \%$ & $15 \%$ & $3 \%$ & $0.30[\mathrm{SD}=0.61]$ \\
Moved in with others to save money & $6 \%$ & $11 \%$ & $2 \%$ & $4 \%$ \\
Moved more than once per year & $5 \%$ & $8 \%$ & $2 \%$ & $8 \%$ \\
Lived with others, not paying rent & $3 \%$ & $5 \%$ & $1 \%$ & $2 \%$ \\
Lived in shelter & $2 \%$ & $4 \%$ & $1 \%$ & $4 \%$ \\
Evicted & $2 \%$ & $3 \%$ & & $2 \%$ \\
\hline
\end{tabular}

Analysis sample includes respondents answering all instability questions at Year 5, excluding those incarcerated at Year 5. All differences between formerly incarcerated and never incarcerated are statistically significant at $\mathrm{P}<.001$. 
Table 2

Demographic and Socioeconomic Characteristics by Incarceration History

\begin{tabular}{|c|c|c|c|c|}
\hline & Full Sample & Ever Incarcerated & Never Incarcerated & Incarceration History Unknown \\
\hline \multicolumn{5}{|l|}{ Early Life } \\
\hline White $^{* * *}$ & $22 \%$ & $13 \%$ & $29 \%$ & $13 \%$ \\
\hline Black $^{* * *}$ & $47 \%$ & $60 \%$ & $38 \%$ & $49 \%$ \\
\hline Hispanic $* *$ & $23 \%$ & $20 \%$ & $25 \%$ & $28 \%$ \\
\hline Other & $7 \%$ & $7 \%$ & $7 \%$ & $9 \%$ \\
\hline Foreign-Born ${ }^{* * *}$ & $15 \%$ & $6 \%$ & $20 \%$ & $24 \%$ \\
\hline Lived with both parents at age $15^{* * *}$ & $44 \%$ & $31 \%$ & $53 \%$ & $36 \%$ \\
\hline Mother experienced depression ${ }^{* * *}$ & $24 \%$ & $28 \%$ & $22 \%$ & $24 \%$ \\
\hline Cognitive Score $(0=\text { low, } 15=\text { high })^{* * *}$ & 6.64 & 6.37 & 6.85 & 6.12 \\
\hline Impulsivity $(0=\text { low, } 6=\text { high })^{* * *}$ & 0.94 & 1.28 & 0.78 & 1.08 \\
\hline \multicolumn{5}{|l|}{ Contemporaneous covariates } \\
\hline Age at baseline ${ }^{* * *}$ & 28.3 & 26.2 & 29.3 & 29.3 \\
\hline Married at baseline ${ }^{* * *}$ & $31 \%$ & $10 \%$ & $45 \%$ & $32 \%$ \\
\hline Cohabiting at baseline $e^{* * *}$ & $39 \%$ & $47 \%$ & $35 \%$ & $37 \%$ \\
\hline Nonresident at baseline ${ }^{* * *}$ & $30 \%$ & $44 \%$ & $20 \%$ & $31 \%$ \\
\hline Baseline education: $<\mathrm{HS}{ }^{* * *}$ & $29 \%$ & $41 \%$ & $22 \%$ & $29 \%$ \\
\hline Baseline education: HS $\operatorname{grad}^{* *}$ & $37 \%$ & $40 \%$ & $34 \%$ & $43 \%$ \\
\hline Baseline education: Some college ${ }^{* * *}$ & $20 \%$ & $16 \%$ & $23 \%$ & $14 \%$ \\
\hline Baseline education: College $\operatorname{grad}^{* * *}$ & $13 \%$ & $2 \%$ & $21 \%$ & $9 \%$ \\
\hline Employed at baseline ${ }^{* * *}$ & $85 \%$ & $76 \%$ & $90 \%$ & $88 \%$ \\
\hline Substance abuse at baseline ${ }^{* * *}$ & $10 \%$ & $17 \%$ & $5 \%$ & $8 \%$ \\
\hline Father in good health at baseline ${ }^{* * *}$ & $73 \%$ & $68 \%$ & $75 \%$ & $76 \%$ \\
\hline \multicolumn{5}{|l|}{$\mathrm{P} \leq .001$} \\
\hline$*^{*} \leq .01$ & & & & \\
\hline $\mathrm{P} \leq .05$ & & & & \\
\hline
\end{tabular}




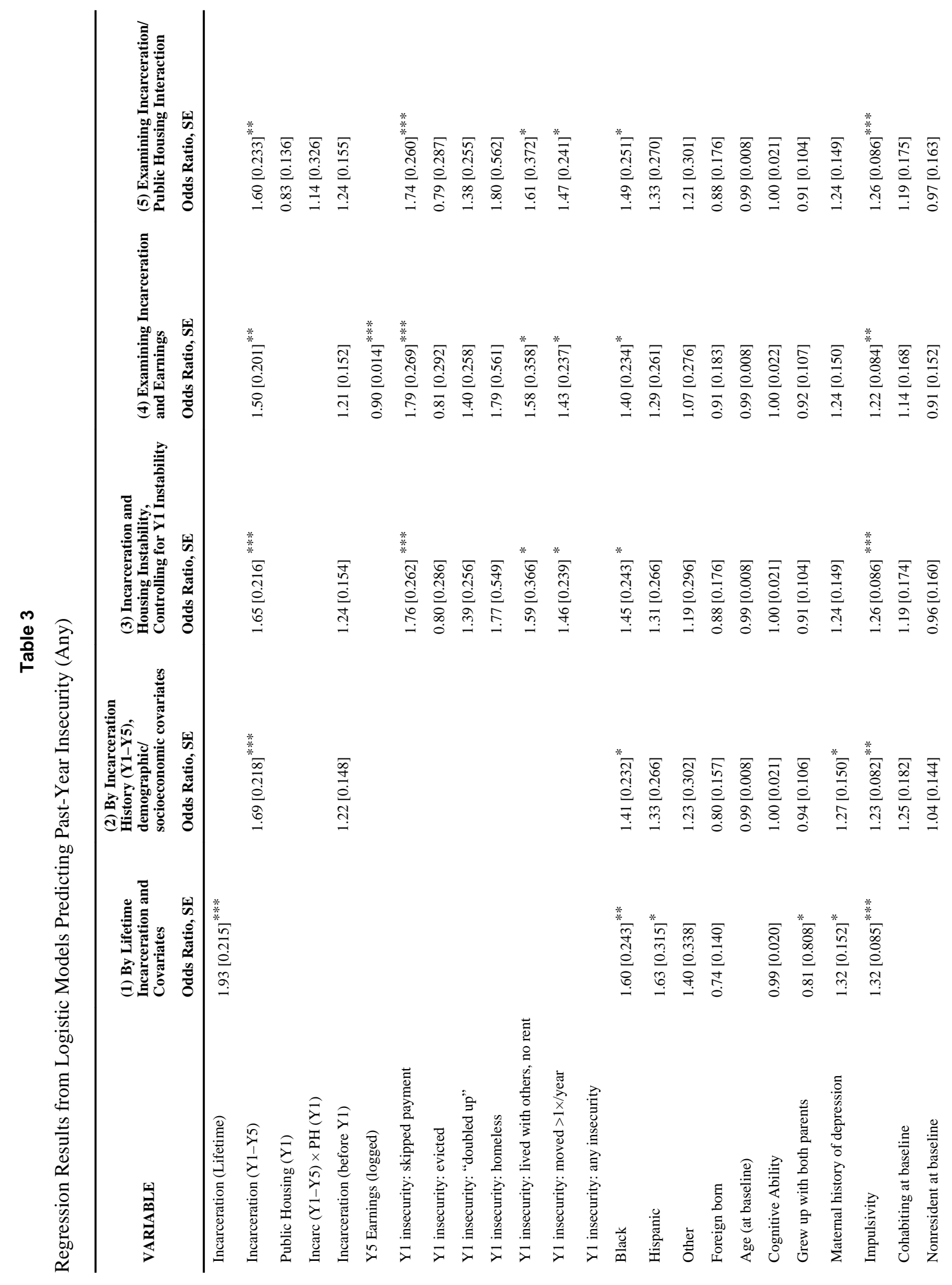




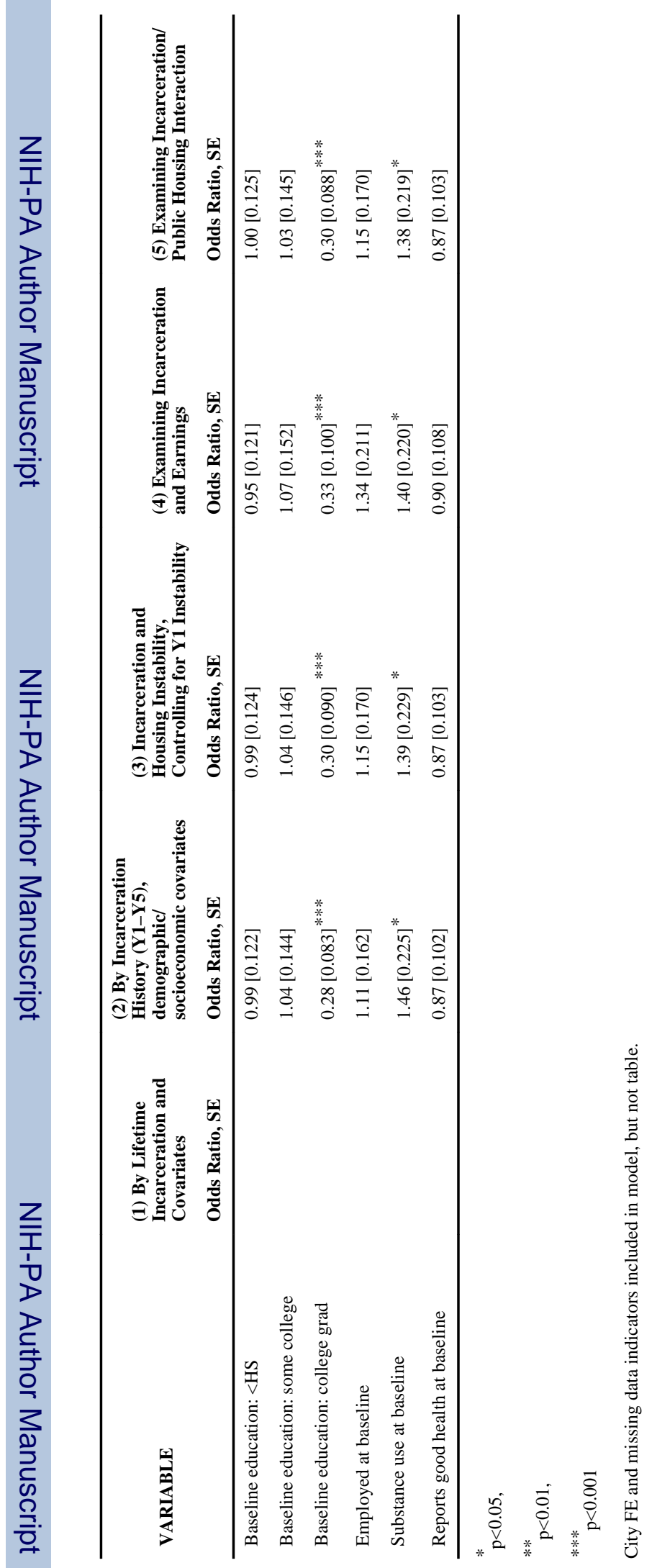




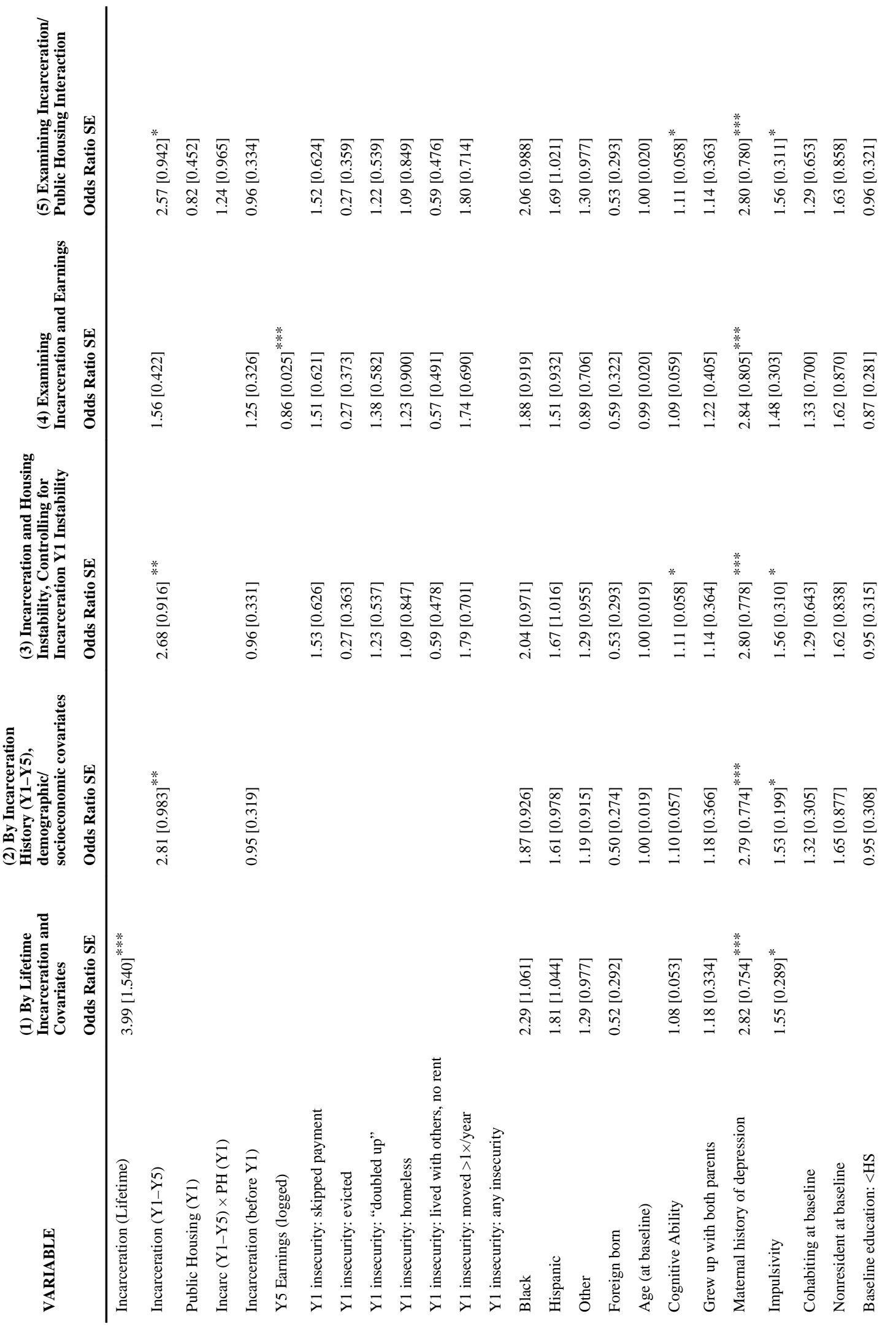




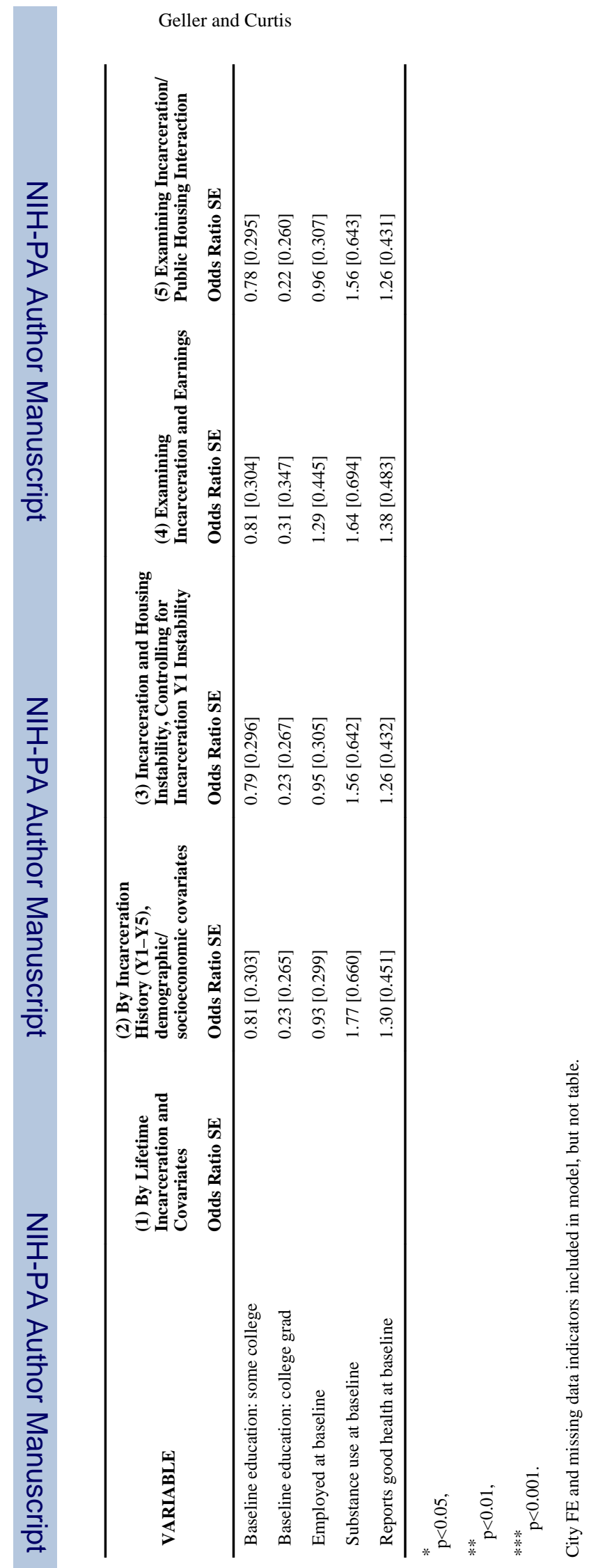

Soc Sci Res. Author manuscript; available in PMC 2012 July 1. 


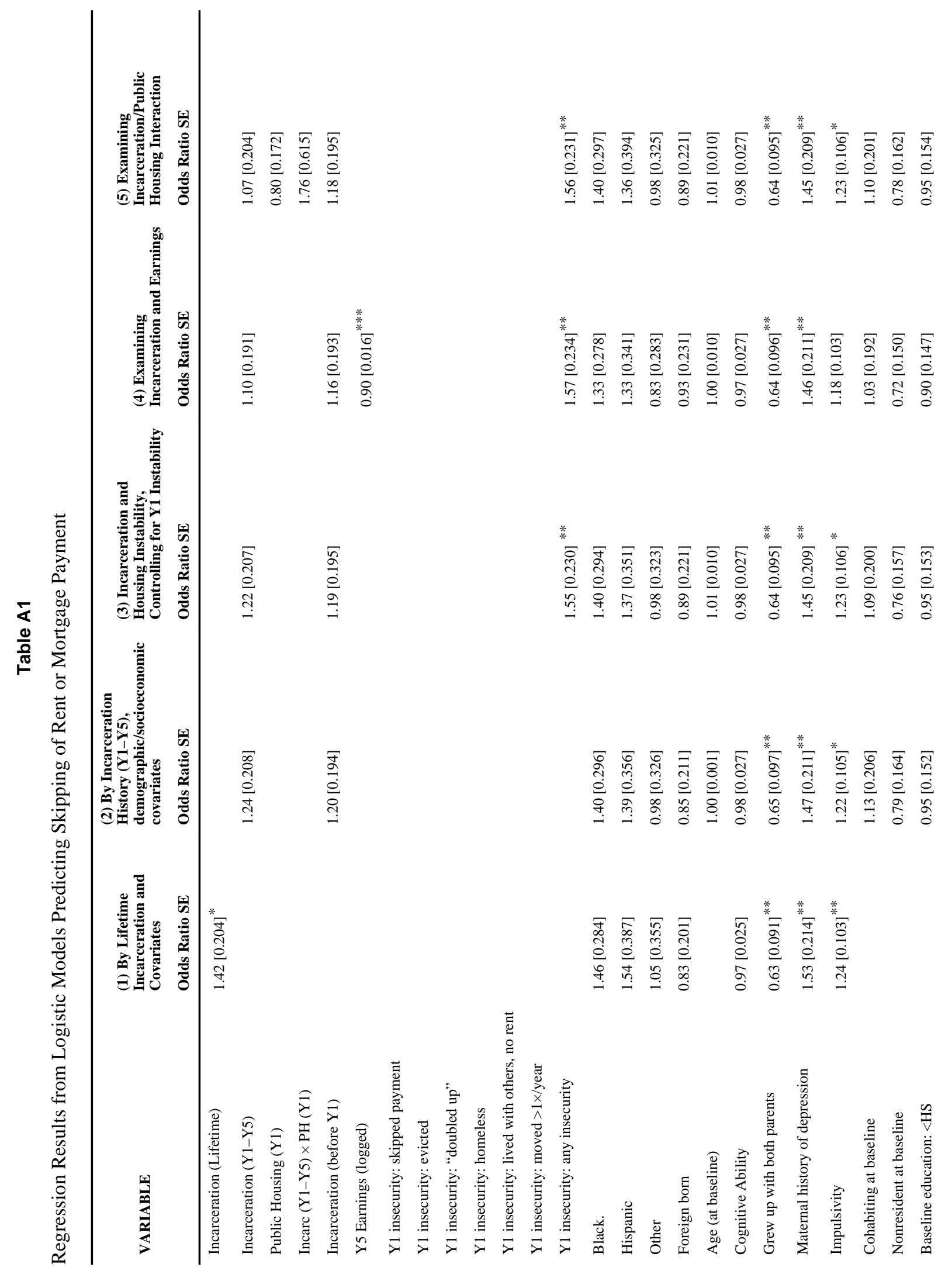




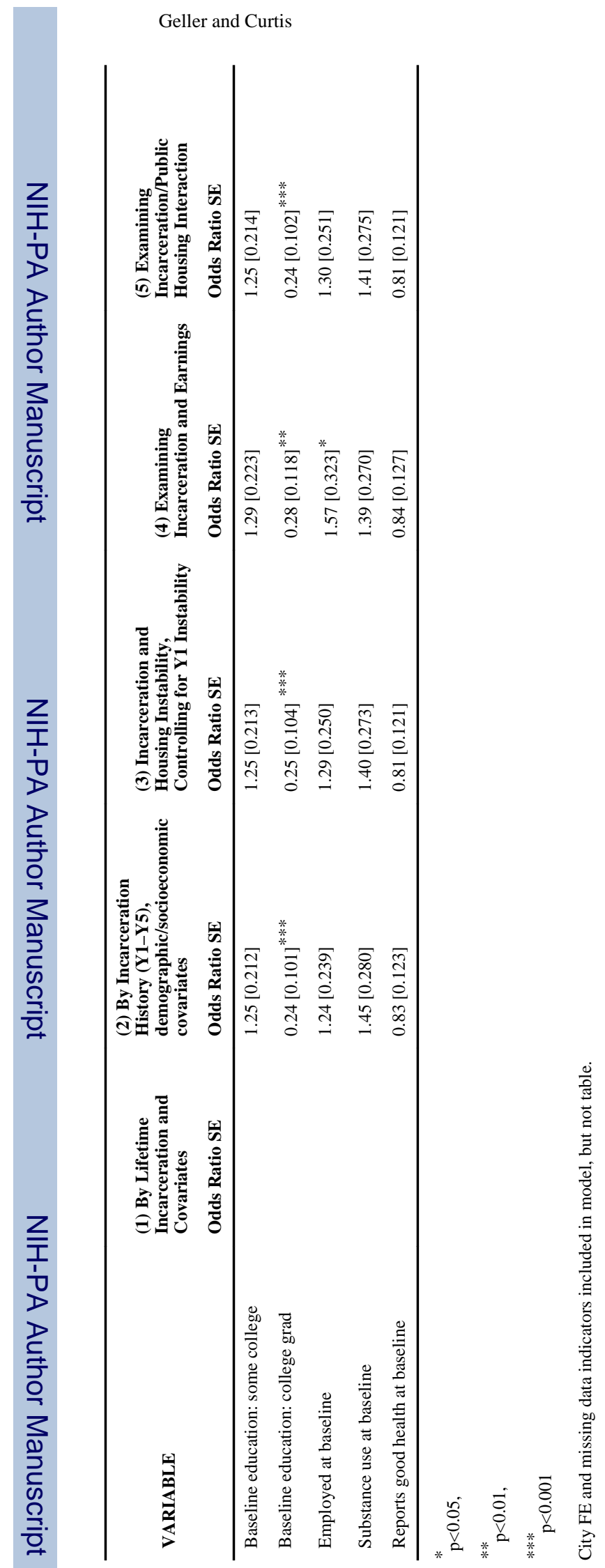

Soc Sci Res. Author manuscript; available in PMC 2012 July 1. 


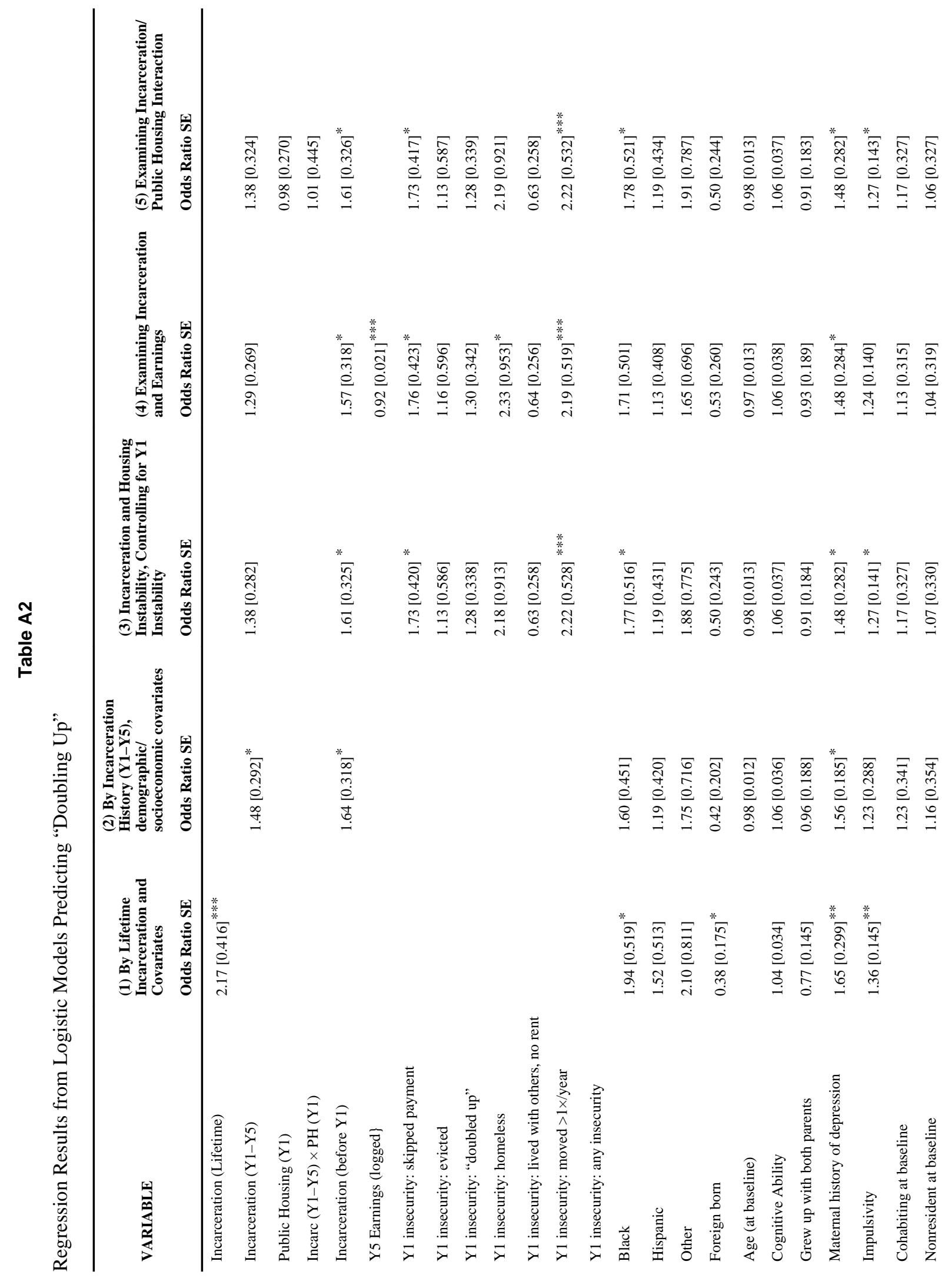




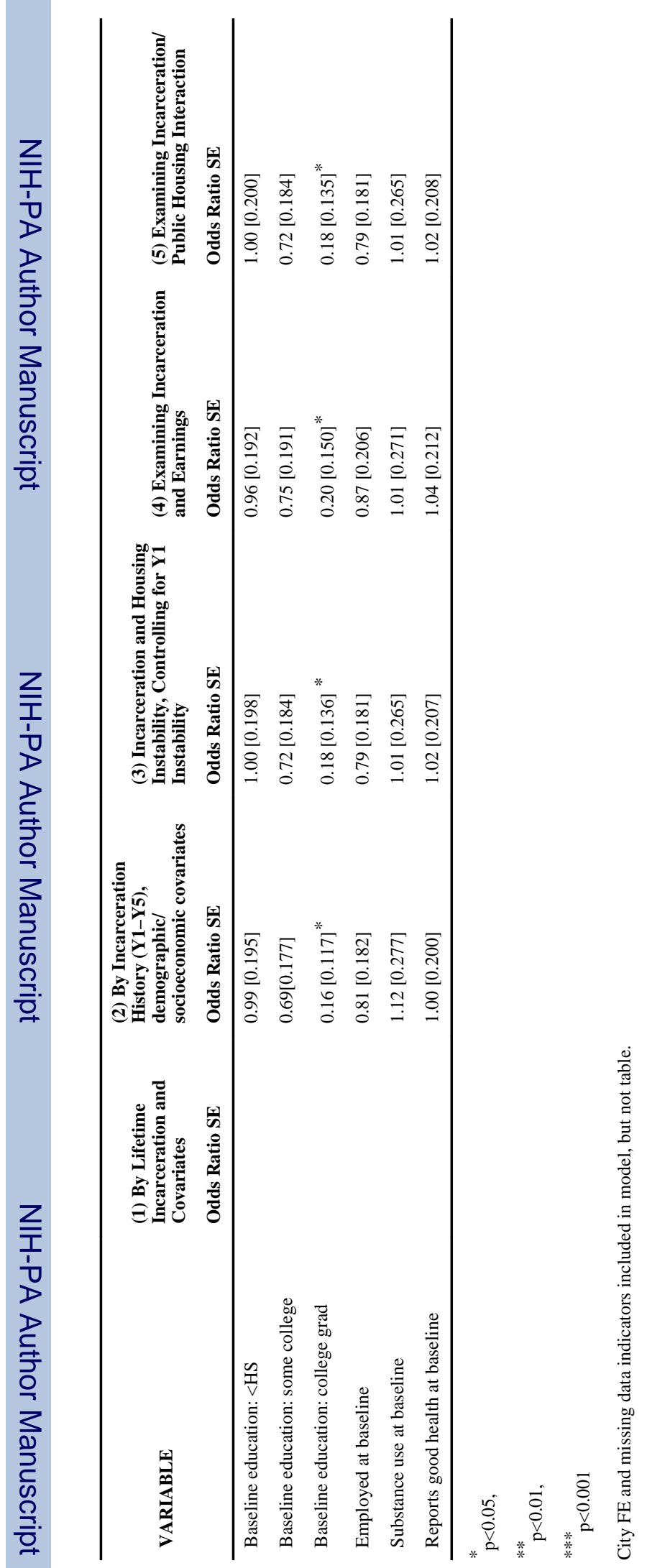




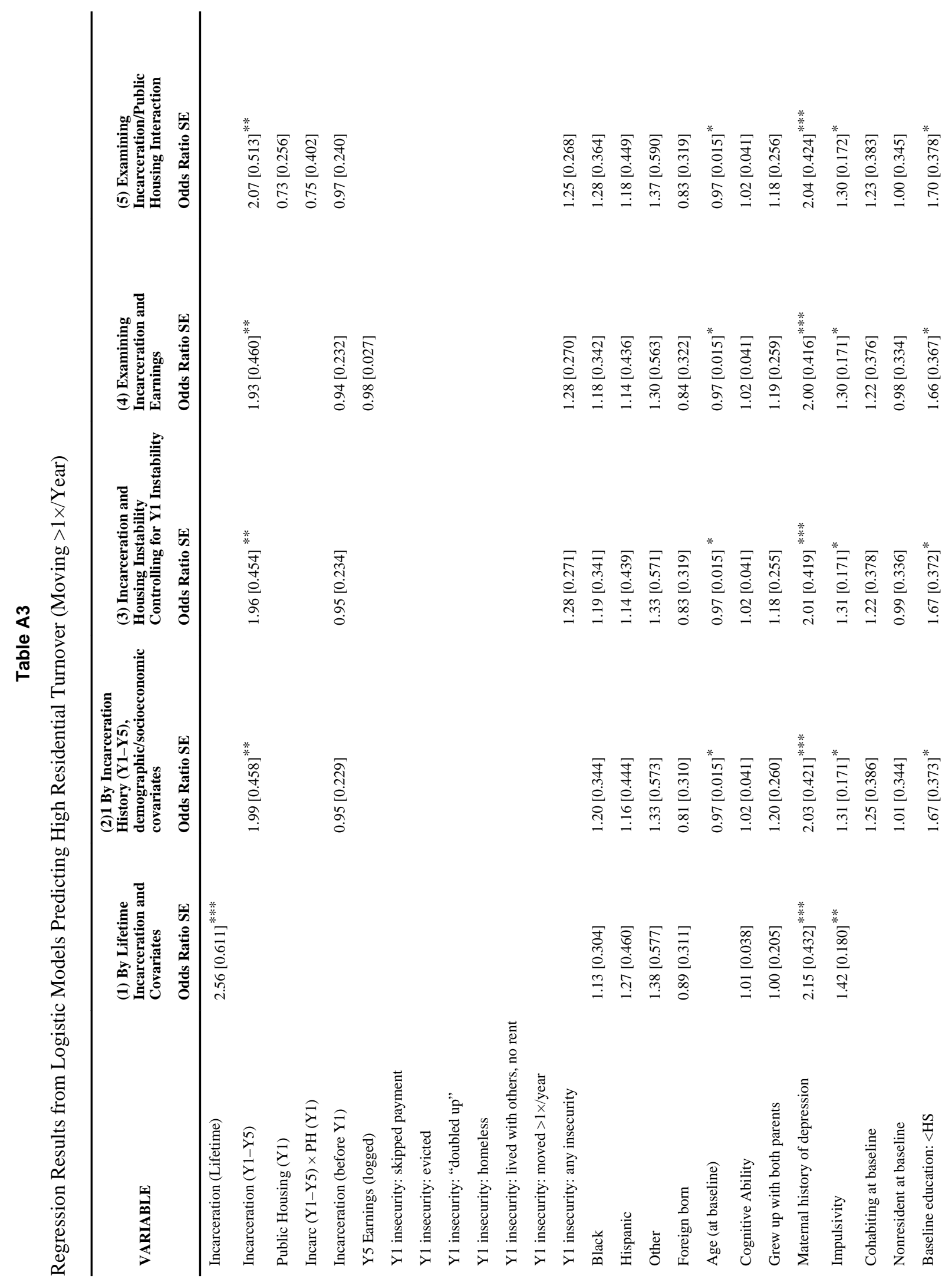




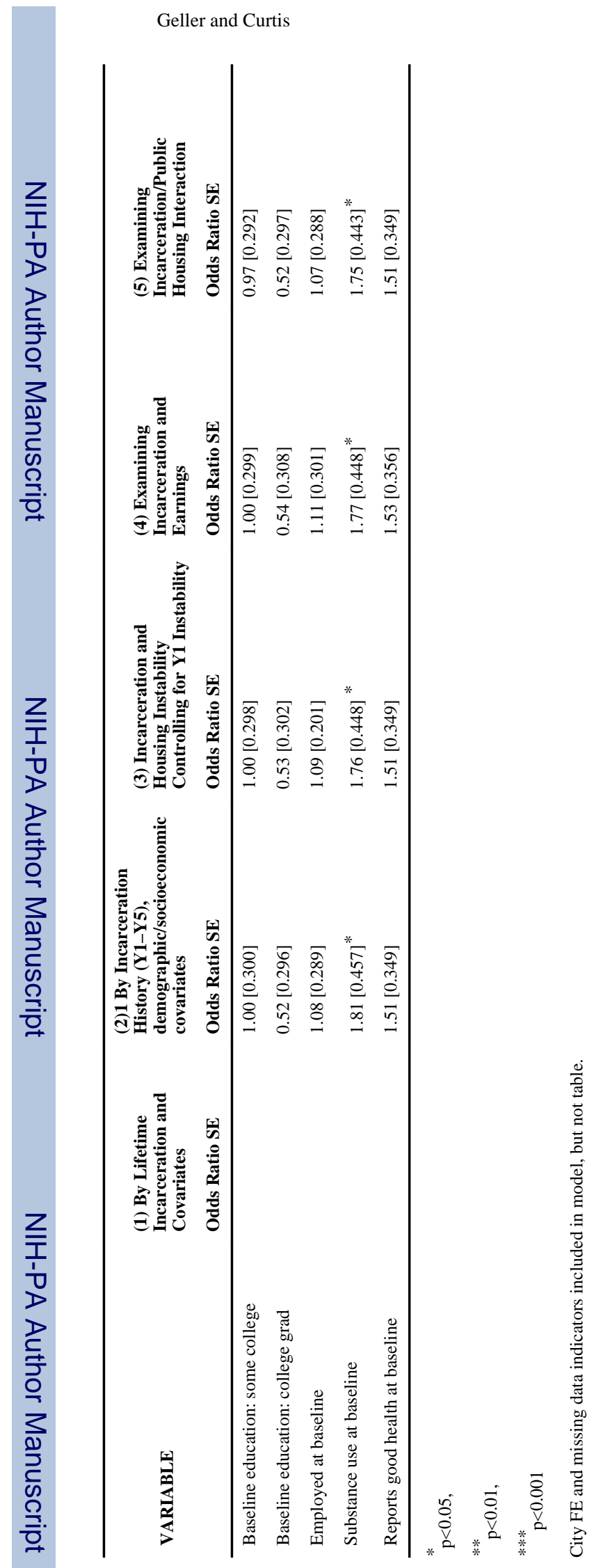

Soc Sci Res. Author manuscript; available in PMC 2012 July 1. 


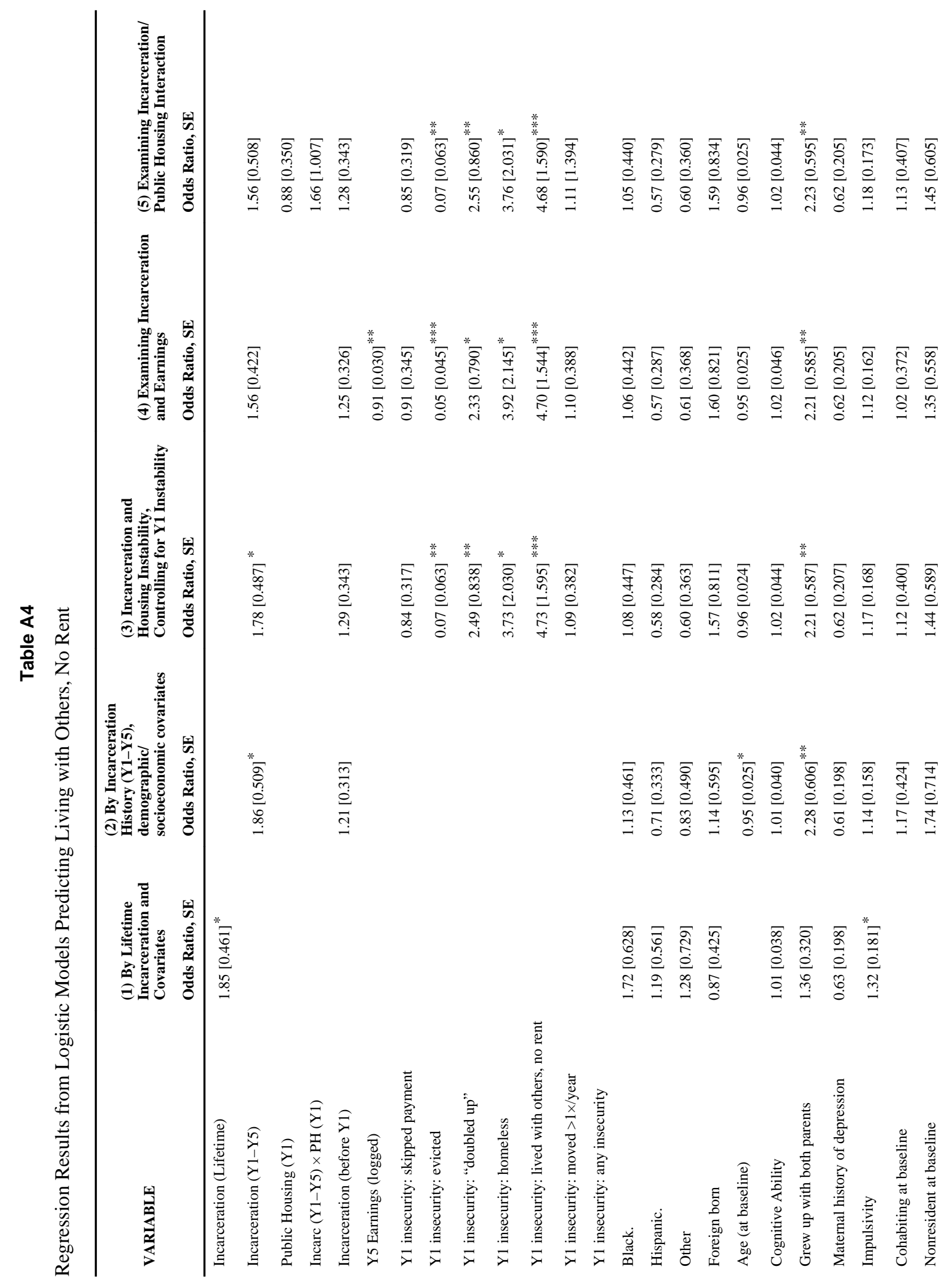




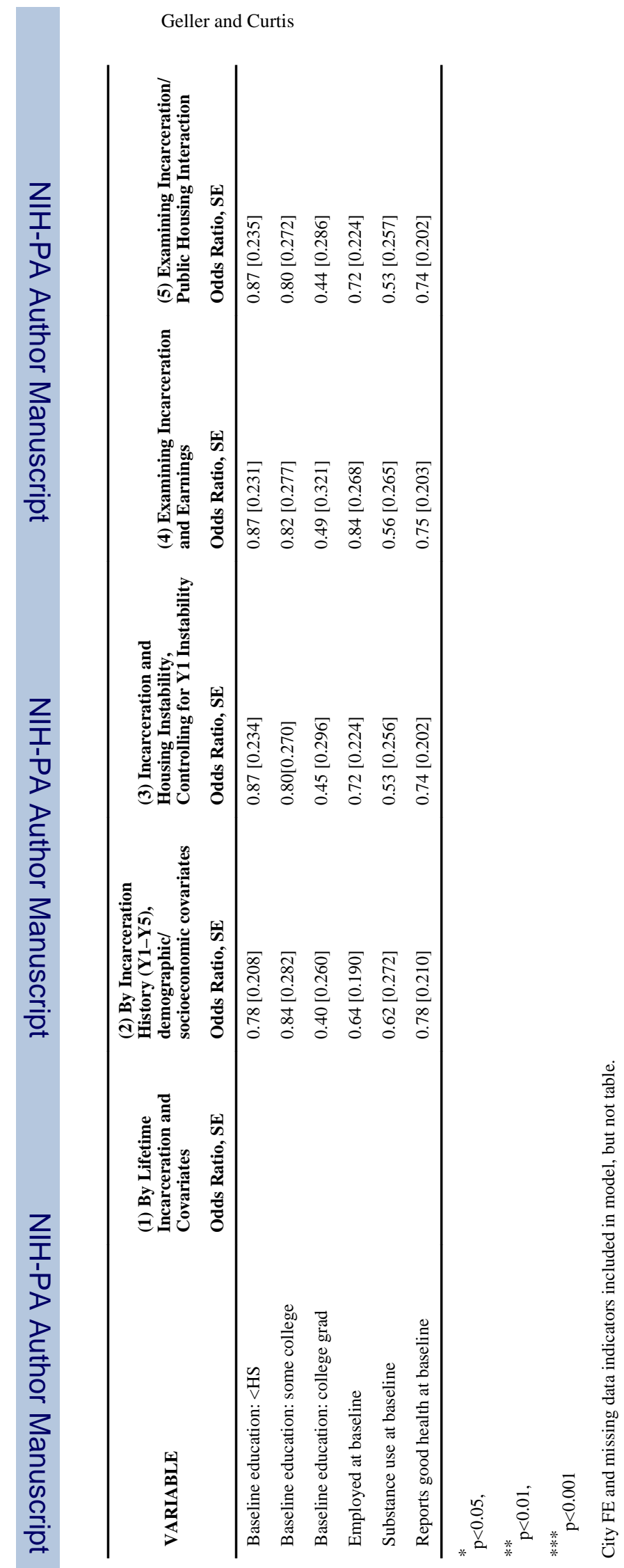

Soc Sci Res. Author manuscript; available in PMC 2012 July 1. 


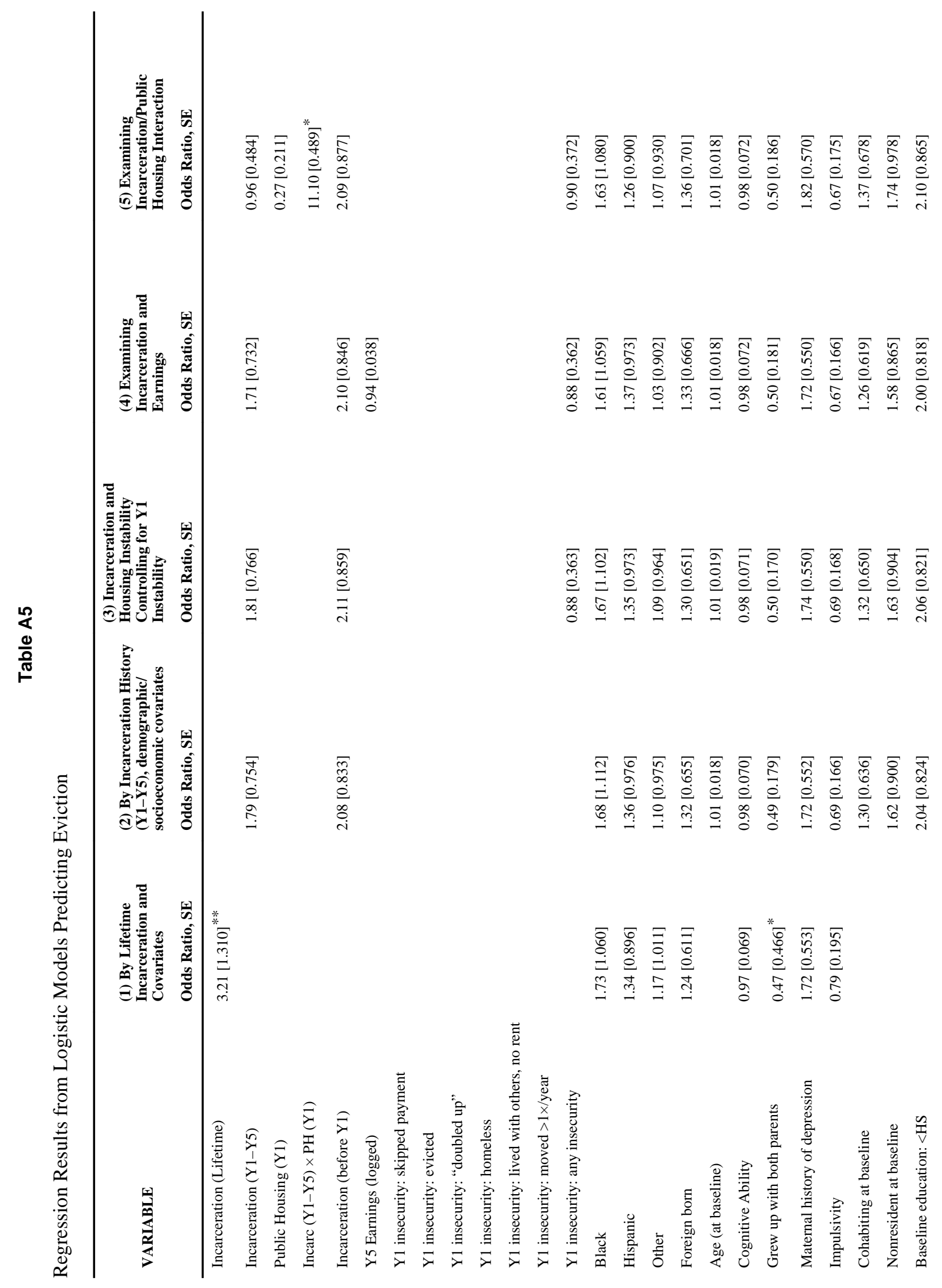




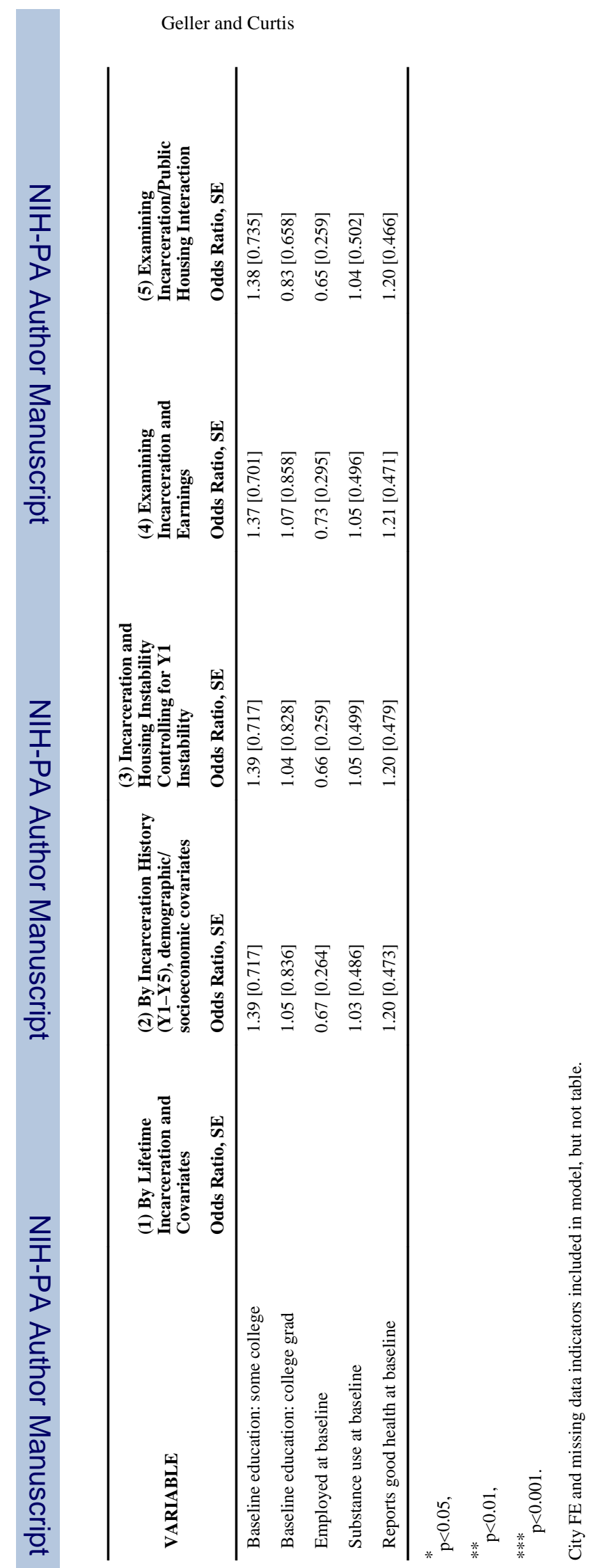

Page 32 